\title{
Object Naming in Dyslexic Children: More Than a Phonological Deficit
}

\author{
SUSANA ARAÚJO \\ LUÍS FAÍSCA \\ INÊS BRAMÃO \\ FILOMENA INÁCIO \\ Universidade do Algarve \\ KARL MAGNUS PETERSSON \\ Universidade do Algarve \\ Karolinska Institutet \\ Max Planck Institute \\ Donders Institute for Brain, Cognition and Behavior \\ ALEXANDRA REIS \\ Universidade do Algarve
}

\begin{abstract}
In the present study, the authors investigate how some visual factors related to early stages of visual-object naming modulate naming performance in dyslexia. The performance of dyslexic children was compared with 2 control groups-normal readers matched for age and normal readers matched for reading level — while performing a discrete naming task in which color and dimensionality of the visually presented objects were manipulated. The results showed that 2-dimensional naming performance improved for color representations in control readers but not in dyslexics. In contrast to control readers, dyslexics were also insensitive to the stimulus's dimensionality. These findings are unlikely to be explained by a phonological processing problem related to phonological access or retrieval but suggest that dyslexics have a lower capacity for coding and decoding visual surface features of 2-dimensional representations or problems with the integration of visual information stored in long-term memory.
\end{abstract}

This work was supported by Fundação para a Ciência e Tecnologia (SFRH/BD/ 28488/2006, PTDC/PSI/64920/2006, PTDC/PSI-PCO/110734/2009, IBB/CBME, LA, FEDER/POCI 2010), the Max Planck Institute for Psycholinguistics, the Donders Institute for Brain, Cognition and Behaviour, Radboud University Nijmegen, and the Swedish Dyslexia Foundation.

Address correspondence to Alexandra Reis, Departamento de Psicologia, Faculdade de Ciências Humanas e Sociais, Campus de Gambelas, Universidade do Algarve, 8005-139 Faro,Portugal; aireis@ualg.pt (e-mail). 
Keywords: dyslexia, object naming, phonology, visual processing

IT HAS BEEN DEMONSTRATED THAT, alongside phonological deficits, visual naming is a major problem in developmental dyslexia and also at relatively mature ages (Ackerman \& Dykman, 1993; Denckla \& Cutting, 1999; Denckla \& Rudel, 1976; Fawcett \& Nicolson, 1994; Jones, Branigan, \& Kelly, 2009; Korhonen, 1995; Veluttino, Fletcher, Snowling, \& Scanlon, 2004). A substantial body of research has documented that dyslexic readers have difficulties in the ability to retrieve verbal labels of familiar objects, showing longer naming latencies than their peers (e.g., Faust \& Sharfstein-Friedman, 2003; Lervåg \& Hulme, 2009; Snowling, van Wagtendonk, \& Stafford, 1988; Truman \& Hennessey, 2006). The object-naming difficulties in dyslexics seem particularly interesting because it suggests that the degree of difficulty cannot easily be ascribed to differential expertise or practice with the testing material, as might be the case for challenges solely with written orthographic stimuli.

Difficulties with phonological encoding and retrieval are well-established deficits in dyslexia, exemplified by the phonological deficit hypothesis of dyslexia (Ramus et al., 2003; Vellutino \& Fletcher, 2007; Veluttino et al., 2004). Although slow naming performance has long been known to be associated with poor reading, the cognitive processes underlying object-naming deficits have not been explored to a great extent and continues to stir considerable debate. Initially, the object naming problem was viewed as symptom of a deficit within the phonological processing system-for example, difficulty with accessing or retrieving phonological word forms, or more generally, less consolidated phonological representations (Clarke, Hulme, \& Snowling, 2005; Faust \& Sharfstein-Friedman, 2003; Katz, 1986; Nation, Marshall, \& Snowling, 2001; Swan \& Goswami, 1997a, 1997b; Truman \& Hennessey, 2006). However, more recently, the interest in exploring the role of other cognitive factors in dyslexia has seen a revival, in particular those related to early visual processing. Despite considerable controversy, a number of studies have identified specific conditions under which dyslexics experience visual processing difficulties. For example, "crowding effects" are particularly marked in dyslexic readers for whom flanked items interfere more with discrimination of a target item than in nondyslexic readers (e.g., Hawelka \& Wimmer, 2005; Pernet, Valdois, Celsis, \& Demonet, 2006; Spinelli, De Luca, Judica, \& Zoccolotti, 2002). Additional findings suggest low-level visual deficits in dyslexia, including deficits related to contrast sensitivity, pattern masking, and motion perception (Di Lollo, Hanson, \& McIntyre, 1983; Scheuerpflug et al., 2004; Skottun, 2000; Slaghuis \& Ryan, 2006; Stein, Talcott, \& Walsh, 2000). What is not well understood is the extent to which visual processes are causally implicated in poor object naming by readers with dyslexia or in slow visual naming in general. Given that object naming depends on perceptual object identification processes, the role of these processes, as a potential source of naming difficulties, is an important target for 
investigation. Object identification occurs when a representation, derived from a picture, activates or matches a corresponding representation in long-term memory. Ease of identification, therefore, depends on, among other things, the efficiency of visual processes in extracting stimulus information (Johnson, Clark, \& Paivio, 1996).

In this study, we investigated whether subjects with dyslexia are at a particular disadvantage when it comes to early visual processing in object naming. A few recent studies have sought to disentangle the influence of visual and phonological processes in serial naming. For example, Jones, Obregón, Kelly, \& Branigan (2008) demonstrated in an eye-movements study that when naming sequences of letters, the performance of dyslexics is particularly poor under conditions of increased visual-orthographic confusion (see also Compton, 2003). In a recent study, Stainthorp and colleagues (2010), investigating the relation between visual processing and poor serial-naming performance, suggested that a deficit in visual features discrimination in slow naming children may hamper the ability to acquire the letter-sound correspondences in the early stages of reading acquisition. To our knowledge, no previous study has directly examined the role of these visual factors in object naming with dyslexic readers.

The main goal of this study was to investigate how some visual factors related to early stages of visual object naming modulate the naming performance in dyslexics. Specifically, assuming that visual feature analysis is fundamental to successful recognition, we examined whether the perceptual visual processing in the extraction of surface features is related to impaired object naming in dyslexics. As emphasized by Johnson, Clark, and Paivio (1996), the initial visual object analysis should be affected by various surface based attributes. For example, surface attributes that index stimulus discriminability (e.g., realism, complexity) are expected to influence the object-naming process. In the current study, we manipulated color and dimensionality in an object-naming task in a fully randomized design. We compared the naming performance of dyslexics and nondyslexic readers on line drawings of objects presented either in color or in black-and-white, as well as on two-dimensional (2D; drawings of common everyday real objects) and the three-dimensional (3D) objects themselves. The performance of dyslexic children was compared to that of a group of reading-matched children and a group of age-matched children. The inclusion of the reading-matched group is important because it allows us to exclude that a given deficit is simply a consequence of the less reading experience in dyslexic children (e.g., "trivial" developmental delay).

The influence of color on object recognition arises at a lower visual processing level, where it helps to differentiate objects and so provides an important source of information in the pre-recognition stage of visual processing (Gegenfurtner \& Rieger, 2000; Wurm, Legge, Isenberg, \& Luebker, 1993). According to Gegenfurtner and Rieger (2000), color information contributes at both the sensory (coding) and cognitive (representation) levels of information processing for object recognition. On the other hand, the extent to which stimuli depict objects 
realistically, which in our study ranges from black-and-white line drawings to real objects, also play a role in object recognition (Johnson et al., 1996). In the current study, we asked whether object naming in dyslexic readers is more (or less) dependent on surface-based representations; in other words, do dyslexic readers benefit differently from color information and the dimensionality of objects in object naming compared to nondyslexic readers? We predicted that if the naming difficulties reflect an underlying pure phonological processing deficit, then dyslexics' performance will be qualitatively similar to that of controls, in the sense that all groups will be equally affected by the visual stimulus manipulation, although there might be quantitative differences such as slower performance in dyslexics. However, if dyslexics are affected by early visual processing deficits with effects on object naming, then a qualitative difference in performance pattern between groups should be observed.

\section{Method}

\section{Participants}

Informed consent was obtained from all the participants' parents in compliance with the Helsinki Declaration. Eighteen dyslexic Portuguese children (11 males and 7 females, $M$ age $=9.5 \pm 1.0$ years) attending a normal school were recruited through clinics that are specialized in children with special needs. Most participants in this group were also enrolled in other studies of our lab (e.g., Araújo, Pacheco, Faísca, Petersson, \& Reis, 2010). All had a formal diagnosis of dyslexia. The inclusion criteria for the dyslexic participants were as follows: normal-range intelligence measured by the Wechsler Intelligence Scale for Children, 3rd ed. (WISC-III; Wechsler, 2006); reading abilities significantly below grade-mean level; absence of neurological, emotional, or attention problems.

The participants' reading achievement was assessed through the 3DM oral reading test (see below), adapted for the Portuguese population from the Differential Diagnosis Dyslexia Battery (Blomert \& Vaessen, 2009). Test-retest reliability was .91. Scores were converted into $z$-scores with reference to normative data, which was collected in a large-scale study with 820 Portuguese children in Grades 1-4 (Reis et al., in preparation). The $z$-scores for the fifth-grade children were estimated through polynomial regression procedures (Van Breukelen \& Vlaeyen, 2005), using the amount of months of formal reading instruction as the predictor. Only those subjects who had reading speed scores at least 1.5 standard deviations below the grade mean level of the normative sample were included in the dyslexic group. The dyslexic group was matched with 19 age-matched controls (13 boys and 6 girls, $M$ age $9.4 \pm 1.0$ years) and 20 reading-matched controls (11 boys and 9 girls, $M$ age $7.3 \pm .5$ years), who were recruited from local schools and classified by their teachers as average pupils. All controls had intelligence scores in the normal range (WISC-III) and reading scores within or above the average (3DM oral 
reading test). As expected, dyslexic readers strongly differed from age-matched controls $(p<.001)$ but not from reading-matched controls $(p=.10)$, in terms of 3DM reading scores. Dyslexics and age-matched controls did not differ in terms of age $(p=.74)$ but differed significantly from the reading-matched control group $(p<.001$ for both $)$.

\section{Reading Test}

The 3DM reading test was composed of two lists of high- and low-frequency words. Each list was composed of 75 stimuli distributed on five sheets (15 stimuli per sheet) of increasing difficulty with respect to the number of syllables (from two to four syllables), syllabic structure (with and without consonant clusters), and phoneme-grapheme correspondence rules (regular and irregular correspondence rules). For each list, the children had $30 \mathrm{~s}$ to read aloud as many words as possible. Reading speed was computed as the number of correctly read words per second.

\section{Object Naming Task}

\section{Stimuli Material}

Fifty-four object drawings, matched to similar real objects, were selected from the set by Snodgrass and Vanderwart (1980). All items were classified according to familiarity and visual ambiguity and had a maximum acquisition age of 7-8 years according to Portuguese norms for the Snodgrass and Vanderwart's set (Ventura, 2003). The objects' attributes were altered to create three experimental conditions: two-dimensional color representations of the objects, two-dimensional black-andwhite $(\mathrm{B} \& \mathrm{~W})$ representations of the objects, and the three-dimensional (3D) real objects. The color and $\mathrm{B} \& \mathrm{~W}$ representations were selected from a set generated by Rossion and Pourtois (2004) and corresponded to the original Snodgrass and Vanderwart's set. The real objects were chosen for their similarity to the objects' representations in terms of size, shape and color (Figure 1).

\section{Procedures}

Two different blocks of stimuli were created. The first block contained two sets of two-dimensional objects: 18 color and $18 \mathrm{~B} \& \mathrm{~W}$ drawings. The second block contained one set of 18 3D objects: the real objects themselves. Each study participant performed both blocks. The order of the blocks and the order of the set of two-dimensional representations were balanced among the subjects in each group. The number of color drawings vs. B\&W drawings versus real objects were also taken into account to ensure that each type of stimulus appeared the same number of times. The two-dimensional representations of objects were displayed on a laptop computer screen using the Presentation Software (Version 7.0, http://nbs.neurobs.com/presentation). The stimuli were displayed at the center of 


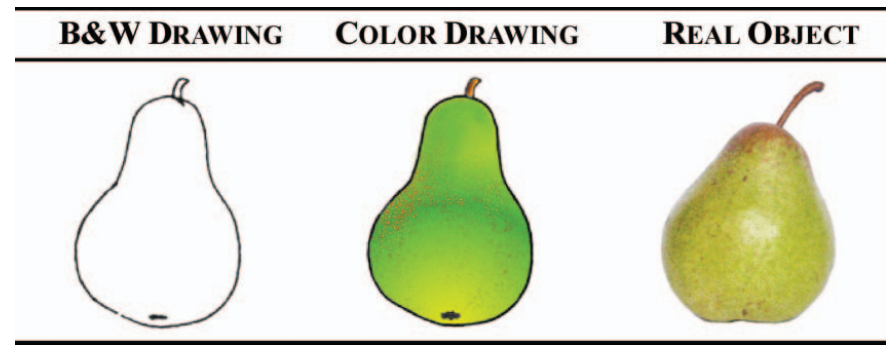

FIGURE 1. Example of a three-dimensional real object and its two-dimensional representations presented in color and in black and white. (Color figure available online.)

the screen for $5 \mathrm{~s}$, followed by a visual fixation cross that appeared for an additional $5 \mathrm{~s}$ before the presentation of the next picture. To test with real objects, the objects were displayed in a $50 \times 50 \times 50 \mathrm{~cm}$ black box located $\sim 50 \mathrm{~cm}$ away that was lit with a lamp for the same display time $(5 \mathrm{~s})$ as the two-dimensional representations. This box was especially constructed for the paradigm, having one open side that allowed a trained examiner to move the objects in and out of the box between trials. The presentation of each object was separated by an interval of $5 \mathrm{~s}$, during which the subjects were instructed to not verbalize anything. Because the whole experiment was performed in a dark room, the subjects could only see the stimulus when the lamp was lit. Participants only saw each stimulus once throughout the experiment, so the same stimulus did not appear in two different conditions. In all presentation modes, subjects were instructed to name the stimuli as quickly and accurately as possible. Accuracy and response times were recorded. Voice detection equipment was used to register response times between the onset of the stimulus display and that of the response. Before the experiment started, we used a specific set of practice items (five practice items per condition), to ensure that the participants were familiar with all experimental procedures and had a satisfactory understanding of the paradigm. Participants were tested individually in three sessions, lasting approximately $30 \mathrm{~min}$ each.

All subjects were first screened to verify their reading and intelligence level in order to select those that took part in the experiment according to the group criteria. The order of the sessions was fixed for all subjects: the 3DM oral reading test and half of the WISC-III battery were given in the first session; the remaining subtests of the WISC-III were given in the second session; and the experimental tasks were administered in the third session. 


\section{Results}

Before statistical analysis was performed, the percentage of correct responses for each item and condition was calculated. To minimize potential differences derived from the quality of or unfamiliarity with the visual information of the items, we excluded items for which more than $50 \%$ of the participants from both groups made incorrect responses in at least one condition. Missing responses were considered incorrect. The following five items were excluded: "padlock," "ash-tray," "frying-pan," "watering-can," and "rolling-pin." Overall, the number of naming errors was small, with a tendency for the dyslexic group (DYS) and the reading-matched controls (CR) to commit more errors (at about 13\%) than the age-matched control group (CA; at about $8 \%$ ).

\section{Response Time Analysis}

For response time analysis (RTs), only the RTs from correct answers were considered. RTs from incorrect answers (4.8\%), no-answers (7.3\%) and unregistered responses (e.g., software failure, subject vocalizations before the naming response [.5\%]) were excluded from the analysis. Mean RTs were calculated for each subject and condition. The data were analyzed with a repeated-measures ANOVA model, considering condition (color drawings vs. B\&W drawings vs. real objects) as a within factor and the reading group (DYS vs. CA vs.CR) as a between factor. The results showed a statistically significant group effect $(F(2,53)=5.6$; $p=.006$; partial $\left.-\eta^{2}=.174\right)$. The CA group had significantly faster response times $(1,402 \mathrm{~ms})$ compared to the DYS group $(1,634 \mathrm{~ms} ; p=.019)$ and the CR group $(1,635 \mathrm{~ms} ; p=.013)$. The DYS and CR groups did not differ significantly from each other $(p=1.0)$. A significant condition effect was also observed $(F(2,11)=$ 13.8; $p<.001$; partial $\left.\eta^{2}=.321\right)$. Color drawings were named faster than $\mathrm{B} \& \mathrm{~W}$ drawings $(p=.002)$ and real objects $(p=.000)$. There was no significant difference between the speed of naming $\mathrm{B} \& \mathrm{~W}$ drawings and real objects $(p=.182)$. The interaction between group and condition was also significant $(F(4,11)=2.5$; $p=.048$; partial $\left.\eta^{2}=.084\right)$. Both control groups showed a condition effect that, in turn, was absent in the DYS group (Tukey HSD; Figure 2).

A post-hoc comparison using the Tukey HSD test showed that the response time of DYS subjects was not affected by the experimental conditions-that is, the DYS group exhibited a constant pattern regardless of the stimulus attributes. In contrast, the $\mathrm{CA}$ group took more time to name $\mathrm{B} \& \mathrm{~W}$ representations and the corresponding real objects compared to color representations $(\mathrm{B} \& \mathrm{~W}$ vs. color drawings, $p=.004$; real objects vs. color drawings, $p=.001$; $\mathrm{B} \& \mathrm{~W}$ vs. real objects, $p=1.0$ ). The $\mathrm{CR}$ participants also named color drawings more quickly than B\&W drawings and real objects. Nevertheless, these differences only reached statistical significance when comparing color representations and real objects $(p=$ .004). Comparisons between groups revealed that the CA group performed the 


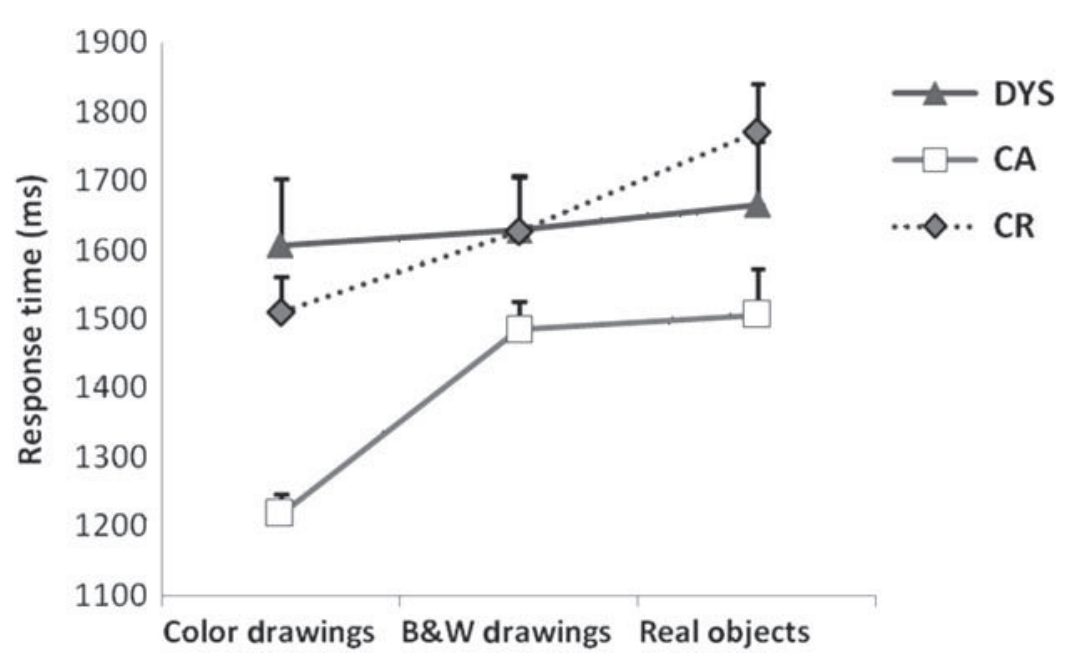

FIGURE 2. Mean naming response times (ms) for the three reading groups. Items are matched across condition and groups. The error bars represent standard error of the mean. $\mathrm{B} \& W=$ black and white; $\mathrm{CA}=$ age-matched controls; $\mathrm{CR}=$ reading-matched controls; $\mathrm{DYS}=$ dyslexics.

task of visual naming of color drawings significantly faster than the DYS group $(p=.005)$. No difference was observed with the remaining conditions (B\&W, $p=.875$; real objects, $p=.80$ ). No significant difference between the DYS and CR groups was found for any condition. Finally, since the experimental groups differed significantly in their response times, we reanalyzed the data following Faust Balota, Spieler, and Ferraro's (1999) suggestions to ensure that the observed significant interaction is not due to an over-additive effect. When the data were standardized with reference to subjects' individual means, the same pattern resulted $(F(4,11)=3.0 ; p=.023)$, indicating that the outlined interaction is not explained by a spurious scale effect.

\section{Discussion}

Object naming is thought to include at least three stages that are typically assumed to occur sequentially: object identification, name retrieval-activation, and response generation (Johnson et al., 1996). In this study we investigated the object naming skills of dyslexic children and normally developing readers and tested to what extent dyslexics and controls are differently affected by changes in the visual attributes of objects, which varied in terms of color (color vs. B\&W) and 
dimensionality (2D vs. 3D). Overall, our results show that dyslexic children are significantly slower in object naming compared to age-matched control readers.

Based on the assumption that the complexity and detail of object representations might influence object naming performance (Gordon, 1997; Johnson et al., 1996), we expected to find distinct patterns of group performance as a function of the surface-based object information available. Previous research provided compelling evidence that color information improves object recognition (Bramão, Faísca, Petersson, \& Reis, 2010; Rossion \& Pourtois, 2004; Vernon \& Lloyd-Jones, 2003; Wurm et al., 1993). Here we found that color representations significantly increased the two-dimensional object naming performance in both age- and reading-matched controls. Dyslexic readers, however, were not sensitive to the color vs. B\&W contrast and, thus, showed no advantage in naming colored over B\&W line-drawings. The dyslexics were also slower at naming color drawings compared to age-matched controls.

Studies of color influence in object recognition show that color contributes to the earliest stages of visual processing via coding as well as to the cognitive levels via representation (Gegenfurtner \& Rieger, 2000). Regarding the influence of color on low-level visual processes, Tanaka, Weiskopf, and Williams (2001) argue that color provides a significant cue for segmenting visual input. From our results, it is not completely clear at which level or levels of visual processing color plays a role in object naming by dyslexics, although it appears to be related to the visual recognition system. For example, it is possible that dyslexics have a lower capacity for coding and decoding surface features of 2D representations. Alternatively (or additionally), color effects could reflect difficulties at a later stage in processing, in the matching of feature and pattern encoding to stored visual representations.

We might also ask if the observed group differences in the color drawing condition lie at a stage of processing when the corresponding phonological representation is accessed and retrieved, as previously suggested (Nation et al., 2001; Truman \& Hennessey, 2006; see also Jones, Branigan, Hatzidaki, \& Obregón, 2010). The pattern of results found in this study challenges this explanation: While naming delays for 2D color representations were greater in the dyslexic group compared to the age-matched control group, both groups performed at a similar level on B\&W drawings and real objects. If it was the case that a fundamental phonological deficit underlies the object-naming problems observed in dyslexia, then dyslexic participants should differ from normal readers also on $\mathrm{B} \& \mathrm{~W}$ drawings and real objects, as all conditions require phonological access and retrieval. However, this was not the case. On the same grounds, the dyslexics' performance cannot be accounted for by differences in semantic activation or articulatory organization of verbal output. Thus, we propose that the group differences found in this study reflect processing differences linked to visual recognition. Here, it is worth mentioning that the fact that our dyslexic sample performed as well as normal readers on $\mathrm{B} \& \mathrm{~W}$ drawings does not seem to fit the idea that they exhibit 
less contrast sensitivity than controls (e.g., Slaghuis \& Ryan, 2006), thus suggesting that the locus of their difficulties reflect other aspects of visual processing. The fact that dyslexics were not affected by the stimulus dimensionality manipulation again raises the possibility that the visual recognition system is "formatted" differently in these subjects in comparison to nondyslexic readers. We argue that the response pattern that characterized dyslexic participants cannot be reduced to a developmental delay, based on the observation that the reading-matched controls and age-matched controls performed quite similarly (they were both affected by the stimulus manipulation). Both control groups showed longer naming delays for real objects compared to color line-drawings, perhaps because real objects are perceptually more complex and require the ability to integrate diverse perceptual features.

Previous studies on object naming in illiterate subjects provide an alternative interpretation of our results. Like dyslexics, illiterate subjects show difficulties in phonological and object-naming tasks (Reis \& Castro-Caldas, 1997; Reis, Guerreiro, \& Castro-Caldas, 1994), and some recent papers show that the comparisons between these two populations are relevant (Carreiras et al., 2009; Reis, Faísca, \& Petersson, in press). In an object-naming study with illiterate and literate subjects, Reis and colleagues suggested that normal reading and writing habits improve visual processing skills of two-dimensional information (e.g., scanning two-dimensional representations, two-dimensional pattern recognition) and that this influences the naming performance of two-dimensional representations (Reis, Petersson, Castro-Caldas, \& Ingvar, 2001). Conceivable, reading difficulties in dyslexia may result in decreased reading and writing habits, and thus, less practice with processing two-dimensional representations. In turn, less practice may prevent the development of normal visual skills for coding, decoding, and generating two-dimensional symbolic representations. The major challenge for this interpretation is the need to disentangle the reciprocal effects between reading and writing skills with visual processing skills per se; in other words, to understand if visual processing differences are a consequence of lower reading skills rather than a cause of reading (and naming) failure itself. In contrast to illiterate subjects, our dyslexic study population has at least theoretically practiced as much as normal readers on coding and decoding two-dimensional representations in terms of figurative and symbolic representations of objects, and thus it seems less likely that our results can be explained by an analogy with illiterate subjects. Note that in this case, dyslexics should have been different from normal readers on B\&W drawings, as was the case for the illiterate and literate subjects studied by Reis, Faísca, Ingvar, and Petersson (2006).

To summarize, although a phonological deficit is well established as a core feature of developmental dyslexia, the results of this study suggest that the processes involved in early visual feature analysis or in the integration of visual information stored in long-term memory might be affected in dyslexia. If this interpretation is correct, then such a deficit can potentially result in less optimal 
information transfer between the visual and language systems during access and retrieval of object names, and thus slows down the naming response. The fact that we found group differences in response times but not in accuracy suggests that the performance of dyslexic readers is related to the speed with which cognitive systems handle information or transfer information between the visual and language systems.

In conclusion, we have emphasized that the current findings highlight the role that differences linked to visual recognition play in poor naming that characterizes dyslexia, but we recognize that further studies are warranted. The implication of what the object naming deficits reflect-whether the difficulties are phonological or non-phonological in nature-is not trivial (for an overview see, for instance, Powell, Stainthorp, Stuart, Garwood, \& Quinlan, 2007; Vellutino, Fletcher, Snowling, \& Scanlon, 2004). The correspondence between the cognitive processes engaged in visual object naming and those involved in reading (e.g., Wolf \& Bowers, 1999) implies that an understanding of the sources of difficulty underlying slow naming performance might transfer directly to related reading difficulties.

\section{AUTHOR NOTES}

Susana Araújo is a PhD student in the Cognitive Neuroscience Research Group, Centre for Molecular and Structural Biomedicine/Institute for Biotechnology and Bioengineering, Universidade do Algarve. Her research is focused on reading and language development. Luís Faísca is assistant professor in the Psychology Department at Universidade do Algarve, Portugal. His main research interests include reading and language development, memory, and quantitative analysis of behavioural data. Inês Bramão is a PhD student in the Cognitive Neuroscience Research Group, Centre for Molecular and Structural Biomedicine/Institute for Biotechnology and Bioengineering, Universidade do Algarve. Her research is focused on object recognition and object naming. Filomena Inácio is a research assistant in the Cognitive Neuroscience Research Group, Centre for Molecular and Structural Biomedicine/Institute for Biotechnology and Bioengineering, Universidade do Algarve. Her main research interests include language, memory, and implicit learning. Karl Magnus Petersson is assistant professor at Universidade do Algarve, a senior scientist at the Max Planck Institute for Psycholinguistics, a research fellow at the Donders Institute for Brain, Cognition and Behavior, and a senior lecturer at the Karolinska Institutet. His research is focused on the cognitive neuroscience of language, reading, and writing and learning and memory, using PET, fMRI, TMS, EEG, and eye-tracking. Alexandra Reis is associate professor at Universidade do Algarve. Her research has focused on the cognitive neuroscience of reading and writing and literacy and illiteracy. She has investigated these research topics with cognitive-behavioral, anatomical, and functional neuroimaging methods.

\section{REFERENCES}

Ackerman, P. T., \& Dykman, R. A. (1993). Phonological processes, confrontational naming, and immediate memory in dyslexia. Journal of Learning Disabilities, 26(9), 597-609. 
Araújo, S., Pacheco, A., Faísca, L., Petersson, K. M., \& Reis, A. (2010). Visual rapid naming and phonological abilities: Different subtypes in dyslexic children. International Journal of Psychology, 45(6), 443-452.

Blomert, L., \& Vaessen, A. (2009). Differentiaal Diagnostiek van Dyslexie; Cognitieve analyse van lezen en spellen [Dyslexia Differential Diagnosis; cognitive analysis of reading and spelling]. Amsterdam: Boom Test Publishers.

Bramão, I., Faísca, L., Petersson, K. M., \& Reis, A. (2010). The influence of surface color information and color knowledge information in object recognition. American Journal of Psychology, 123, 459-468.

Carreiras, M., Seghier, M. L., Baquero, S., Estévez, A., Lozano, A., Devlin, J. T., et al. (2009, October). An anatomical signature for literacy. Nature, 461(15), 983-988.

Clarke, P., Hulme, C., \& Snowling, M. (2005). Individual differences in RAN and reading: A response timing analysis. Journal of Research in Reading, 28(2), 73-86.

Compton, D. L. (2003). The influence of item composition on RAN letter performance in first-grade children. The Journal of Special Education, 37(2), 81-94.

Denckla, M. B., \& Cutting, L. E. (1999). History and significance of rapid automatized naming. Annals of Dyslexia, 49, 29-42.

Denckla, M. B., \& Rudel, R. G. (1976). Rapid "automatized" naming (RAN): Dyslexia differentiated from other learning disabilities. Neuropsychologia, 14, 471-479.

Di Lollo, V., Hanson, D., \& McIntyre, J. (1983). Initial stages of visual information processing in dyslexia. Journal of Experimental Psychology: Human Perception and Performance, 9(6), 923-935.

Fawcett, A. J., \& Nicolson, R. I. (1994). Naming speed in children with dyslexia. Journal of Learning Disabilities, 27, 641-646.

Faust, M. E., Balota, D. A., Spieler, D. H., \& Ferraro, F. R. (1999). Individual differences in information-processing rate and amount: Implications for group differences in response latency. Psychological Bulletin, 125, 777-799.

Faust, M., \& Sharfstein-Friedman, S. (2003). Naming difficulties in adolescents with dyslexia: Application of the tip-of-the-tongue paradigm. Brain and Cognition, 53, 211-217.

Gegenfurtner, K. R., \& Rieger, J. (2000). Sensory and cognitive contributions of color to the recognition of natural scenes. Current Biology, 10, 805-808.

Gordon, B. (1997). Models of naming. In H. Goodglass \& A. Wingfield (Eds.), Anomia: Neuroanatomical and cognitive correlates (pp. 31-64). New York, NY: Academic Press.

Hawelka, S., \& Wimmer, H. (2005). Impaired visual processing of multi-element arrays is associated with increased number of eye movements in dyslexic reading. Vision Research, $45,855-863$.

Johnson, C. J., Clark, J. M., \& Paivio, A. (1996). Cognitive components of picture naming. Psychological Bulletin, 120(1), 113-139.

Jones, M. W., Branigan, H. P., Hatzidaki, A., \& Obregón, M. (2010). Is the "naming” deficit in dyslexia a misnomer? Cognition, 116, 56-70.

Jones, M. W., Branigan, H. P., \& Kelly, M. L. (2009). Dyslexic and nondyslexic reading fluency: Rapid automatized naming and the importance of continuous lists. Psychonomic Bulletin \& Review, 16(3), 567-572.

Jones, M. W., Obregón, M., Kelly, M. L., \& Branigan, H. P. (2008). Elucidating the component processes involved in dyslexic and non-dyslexic reading fluency: An eyetracking study. Cognition, 109, 389-407.

Katz, R. B. (1986). Phonological deficiencies in children with reading disability: Evidence from an object-naming task. Cognition, 22, 225-257.

Korhonen, T. T. (1995). The persistence of rapid naming problems in children with reading disabilities: A nine-year follow-up. Journal of Learning Disabilities, 28(4), 232-239. 
Lervåg, A., \& Hulme, C. (2009). Rapid automatized naming (RAN) taps a mechanism that places constraints on the development of early reading fluency. Psychological Science, 20(8), 1040-1048.

Nation, K., Marshall, C. M., \& Snowling, M. J. (2001). Phonological and semantic contributions to children's picture naming skill: Evidence from children with developmental reading disorders. Language and Cognitive Processes, 16(2/3), 241-259.

Pernet, C., Valdois, S., Celsis, P., \& Demonet, J. F. (2006). Lateral masking, levels of processing and stimulus category: A comparative study between normal and dyslexic readers. Neuropsychologia, 44, 2374-2385.

Powell, D., Stainthorp, R., Stuart, M., Garwood, H., \& Quinlan, P. (2007). An experimental comparison between rival theories of rapid automatized naming performance and its relationship to reading. Journal of Experimental Child Psychology, 98, 46-68.

Ramus, F., Rosen, S., Dakin, S. C., Day, B. L., Castellote, J. M., White, S., et al. (2003). Theories of developmental dyslexia: Insights from a multiple case study of dyslexic adults. Brain, 126, 841-865.

Reis, A., Castro, S. L., Inácio, F., Pacheco, A., Araújo, S., Santos, M., et al. (In preparation). Versão Portuguesa da Bateria 3DM para avaliação da leitura e da escrita [3DM Portuguese version to assess reading and spelling skills]. Manuscript in preparation.

Reis, A., \& Castro-Caldas, A. (1997). Illiteracy: A bias for cognitive development. Journal of International Neuropsychological Society, 3, 444-450.

Reis, A., Faísca, L., Ingvar, M., \& Petersson, K. M. (2006). Color makes a difference: Two-dimensional object naming in literate and illiterate subjects. Brain and Cognition, 60, 49-54.

Reis, A., Faísca, L., \& Petersson, K. M. (in press). Literacia: Modelo para o estudo de uma aprendizagem específica na cognição e nas suas bases cerebrais [Literacy: A model to study specific learning in cognition and in its brain implementation]. In J. Mosquera, A. Trevisan \& V. Wannmacher Pereira (Eds.), Alfabeltização e cognição. Porto Alegre, Brazil: Edipucrs.

Reis, A., Guerreiro, M., \& Castro-Caldas, A. (1994). Influence of educational level of non brain-damaged subjects on visual naming capacities. Journal of Clinical and Experimental Neuropsychology, 16, 939-942.

Reis, A., Petersson, K. M., Castro-Caldas, A., \& Ingvar, M. (2001). Formal schooling influences two- but not three-dimensional naming skills. Brain and Cognition, 47, 397-411.

Rossion, B., \& Pourtois, G. (2004). Revisiting Snodgrass and Vanderwart's object pictorial set: The role of surface detail in basic-level object recognition. Perception, 33, 217-236.

Scheuerpflug, P., Plume, E., Vetter, V., Schulte-Koerne, G., Deimel, W., Bartling, J., et al. (2004). Visual information processing in dyslexic children. Clinical Neurophysiology, $115,90-96$.

Skottun, B. C. (2000). The magnocellular deficit theory of dyslexia: The evidence from contrast sensitivity. Vision Research, 40, 111-127.

Slaghuis, W. L., \& Ryan, J. F. (2006). Directional motion contrast sensitivity in developmental dyslexia. Vision Research, 46, 3291-3303.

Snodgrass, J. G., \& Vanderwart, M. (1980). A standardized set of 260 pictures: Norms for name agreement, image agreement, familiarity, and visual complexity. Journal of Experimental Psychology: Learning, Memory and Cognition, 6, 174-215.

Snowling, M., van Wagtendonk, B., \& Stafford, C. (1988). Object naming deficits in developmental dyslexia. Journal of Research in Reading, 11(2), 67-85.

Spinelli, D., De Luca, M., Judica, A., \& Zoccolotti, P. (2002). Crowding effects on word identification in developmental dyslexia. Cortex, 38, 179-200.

Stein, J., Talcott, J., \& Walsh, V. (2000). Controversy about the visual magnocellular deficit in developmental dyslexics. Trends in Cognitive Sciences, 4(6), 209-211. 
Swan, D., \& Goswami, U. (1997a). Phonological awareness deficits in developmental dyslexia and the phonological representations hypothesis. Journal of Experimental Child Psychology, 66, 18-41.

Swan, D., \& Goswami, U. (1997b). Picture naming deficits in developmental dyslexia: The phonological representations hypothesis. Brain and Language, 56, 334-353.

Tanaka, J., Weiskopf, D., \& Williams, P. (2001). The role of color in high-level vision. Trends in Cognitive Sciences, 5(5), 211-215.

Truman, A., \& Hennessey, N. W. (2006). The locus of naming difficulties in children with dyslexia: Evidence of inefficient phonological encoding. Language and Cognitive Processes, 21(4), 361-393.

Van Breukelen, G. J. P., \& Vlaeyen, J. W. S. (2005). Norming clinical questionnaires with multiple regression: The pain cognition list. Psychological Assessment, 17(3), 336-344.

Vellutino, F. R., \& Fletcher, J. M. (2007). Developmental dyslexia. In M. J. Snowling \& C. Hulme (Eds.), The science of reading: A handbook (pp. 362-378). Oxford, England: Blackwell.

Veluttino, F. R., Fletcher, J. M., Snowling, M. J., \& Scanlon, D. M. (2004). Specific reading disability (dyslexia): What have we learned in the past four decades? Journal of Child Psychology and Psychiatry, 45(1), 2-40.

Ventura, P. (2003). Normas para figuras corpus de Snodgrass e Vanderwart (1980). Laboratório de Psicologia, 1(1), 5-19.

Vernon, D., \& Lloyd-Jones, T. (2003). The role of the colour implicit and explicit memory performance. The Quarterly Journal of Experimental Psychology, 56A, 779-802.

Wurm, L. H., Legge, G. E., Isenberg, L. M., \& Luebker, A. (1993). Color improves object recognition in normal and low vision. Journal of Experimental Psychology: Human Perception and Performance, 19, 899-911.

Original manuscript received November 19, 2010

Final version accepted April 14, 2011 